\title{
Editorial
}

\section{Making the best of international conferences}

Above all the must-be-there events on the calendar of nutrition scientists is the International Congress on Nutrition (ICN), held every four years in association with our world representative body the International Union of Nutritional Sciences (IUNS). The 19th ICN takes place in Bangkok next month, with a timely if visionary theme of 'Nutrition Security For All'(1).

\section{The World Public Health Nutrition Association}

The World Public Health Nutrition Association will be launched in Bangkok. A distinguished group of public health nutritionists are active in the interim board and we look forward to starting the individual membership recruitment, under the IUNS umbrella. Lots of colleagues worldwide are excited to come to Bangkok for the 19th ICN in October.

\section{It's good to meet}

Over the years, I have learnt the importance of networking. This is how we can inspire and support each other in the belief that we are here to build something new, something stronger than our day-to-day individual, academic matters such as publishing and attracting funding. The most important things that happen at big conferences are for me the meetings between colleagues - new colleagues as well as those who over the years have become dear friends. At big meetings like the ICN what I value most of all are the breaks and the smaller sessions, when you get to discuss with colleagues how to solve problems and how to move forward.

Plenary speakers set the tone of the conference, and get the participants to think in new directions and to start up new and developing debates. The venue is important when it comes to attracting large numbers of participants but the venue also has to invite meetings outside the scheduled appointments. The didactics or the format used is important for engaging participants in discussions.

\section{But the price is high}

The Bangkok ICN will I am sure be a great success, in its own terms. But judging from its programme it has failed to address or resolve three issues that concern conscientious nutrition scientists. First, of the nine keynote speakers and plenary lecturers, only one is a woman. But the great majority of the students I have trained for over 20 years are talented and hard-working women. What will they think? What kind of future are they going to meet? At high levels nutrition science remains dominated by men. This is bad for the profession. There are many highly qualified female nutrition scientists who are being overlooked when scientific programme committees dominated by men make choices of key speakers.

The Bangkok ICN has also failed to address concerns about cost and control. At \$US 600-800 the registration fee is too high. It is time seriously to consider downscaling nutrition conferences; we do not need fancy lunches or dinners, we do not need fancy printed abstracts, and we certainly do not need another conference bag. True, the student registration fee is lower at \$US 200-300 but this is still a lot of money when added to the travel and accommodation cost.

A downscale of the whole arrangement would probably make it possible for another set of colleagues to come forward and attend - maybe they are the ones who can provide the best solutions of all.

\section{We need a Bangkok Declaration on Nutrition Security for All?}

And finally, why is there no suggestion of a position document being produced during the conference. At public health conferences ${ }^{(2)}$, a statement or manifesto or declaration $^{(3,4)}$ is often produced, to form a backbone for future work. Perhaps it is time to work on such a document? In the shadow of the economic crisis, such a document would be badly needed for us as professionals as well as for our younger students and colleagues-to-be.

\section{True involvement of an engaged audience}

Every time I go to a conference, it amazes me how you can place so many talented and well-educated people in a conference facility without using their expertise and commitment for further work. Surely it must be possible to use a more participatory approach in the planning of conferences, with workshops and more involved discussions than the traditional conference format?

To move forward we need to reach a broadly and deeply inspired mindset combined with a solid feeling of ownership, involvement, mobilisation and commitment 
from policy makers, academia and field workers. This could happen in Bangkok!

Agneta Yngve

Editor-in-Chief

\section{References}

1. ICN (2009) Homepage - 19th International Congress of Nutrition, 4-9 October 2009, BITEC, Bangkok, Thailand. http://www.icn2009.com/index.htm (accessed July 2007).
2. Cannon G (2009) Out of the Box. Public Health Nutr 12, $1584-1587$.

3. O'Neill M, Dupere S, Pedneault E, Perreault K, Forster M, Roberge N, Parent P \& Perreault R (2007) The 'Montreal message': the Ottawa Charter for health promotion is still useful for today's public health practice. Promot Educ Suppl. 2, 31-32, 48-49, 61-62.

4. Porter C (2007) Ottawa to Bangkok: changing health promotion discourse. Health Promot Int 22, 72-79.

doi:10.1017/S1368980009990899

It is with great sadness that we record the untimely death in June of Sheila Bingham, a highly valued member of the world nutrition community and of our Editorial Board. As a colleague said on hearing of her death: 'What a lovely lady. What a good scientist. Damn'. Those of us who had the privilege of knowing Sheila over many years will miss her as a friend and colleague. She was so dedicated to her work, had such passion for nutrition, and worked so hard to make sure things were done properly.Sheila was a rare and special person. When the UK nutritional epidemiology group was formed in 1986, she was prepared to share her ideas and concerns on the apparent ignorance about how to assess the validity of dietary surveys. This openness helped all of us in our struggles to do things better and improve the quality of the evidence base in the interests of public health. Sheila also contributed hugely to our understanding of the relationship between food, nutrition and cancer. In a future issue we plan a paper that will summarise her important contribution to nutrition learning, teaching and practice. 